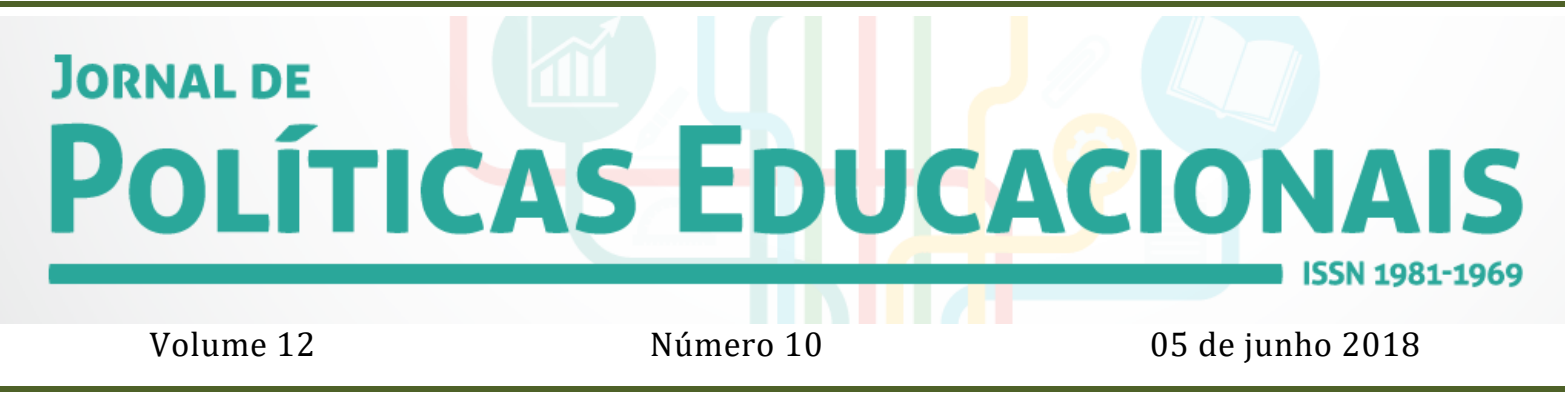

\title{
Política de Assistência Estudantil: repercussões sobre a sua contribuição
}

\author{
Student Assistance Policy: repercussions on its contribution \\ Política de asistencia estudiantil: repercusiones sobre su contribución \\ Juliana Cavalcanti Macedo ${ }^{1}$
Ana de Fátima Pereira de Sousa Abranches
}

Citação: MACEDO, J. C.; ABRANCHES, A. F. P. S. Política de Assistência Estudantil: repercussões sobre a sua contribuição. Jornal de Políticas Educacionais. V. 12, n. 10. Junho de 2018.

http://10.5380/jpe.v12i0.58615

\section{Resumo}

Esta pesquisa apresenta como elemento principal a relação entre o ensino superior e as políticas públicas educacionais de assistência estudantil, na tentativa de uma aproximação entre aquilo que é discutido sobre o assunto na literatura especializada, e o que ocorre efetivamente em uma realidade empírica, no âmbito de uma instituição de ensino superior. A pesquisa teve como principal objetivo analisar a política de assistência estudantil da Universidade Federal Rural de Pernambuco (UFRPE), a partir da percepção dos estudantes beneficiados. A importância desta pesquisa está na possibilidade de se discutir a contribuição da assistência estudantil compreendendo-a como parte da política educacional. Quanto à metodologia, a investigação apresentou enfoques qualitativo e quantitativo, seguindo etapas complementares que visaram contribuir na coleta, análise e interpretação dos dados. Para tanto, realizou-se o levantamento de dados secundários sobre as principais temáticas da pesquisa, e no trabalho de campo, foram aplicados questionários com estudantes beneficiados pela política. Os dados analisados demonstram que a maioria dos estudantes avalia como boa a política de assistência estudantil da UFRPE, assim como, afirma que a assistência estudantil contribui muito para a sua permanência na universidade. Contudo, também revela algumas situações que precisam ser reavaliadas e melhoradas.

Palavras-chave: Assistência Estudantil; Política Pública Educacional; UFRPE.

\footnotetext{
${ }^{1}$ Mestra em Educação, Culturas e Identidades (UFRPE/Fundaj). Pedagoga na Universidade Federal Rural de Pernambuco. E-mail: julianacmacedo@gmail.com

${ }^{2}$ Doutora em Educação (UFPE). Professora do Programa de Pós-Graduação em Educação, Culturas e Identidades da Universidade Federal Rural de Pernambuco e Fundação Joaquim Nabuco. E-mail: anafpsa@gmail.com
} 


\begin{abstract}
This research presents as main element the relationship between higher education and public educational policies of student assistance, focusing at what is discussed on the subject in the specialized literature, and what actually occurs in an empirical reality, in a higher education institution. A research objective was the analysis of that public policy at Federal University of Pernambuco (UFRPE), from the perception of the beneficiary students. The importance of this research is on the possibility of verifying the student assistance policy contribution. Regarding the methodology, the research used qualitative and quantitative approaches, following complementary steps to contribute to the collection, analysis and interpretation of the data. In order to do so, secondary data were collected on the main themes of the research, and questionnaires were applied with students benefited by the policy. The analyzed data show that most of the students evaluate as good the UFRPE policy of student assistance, as well as, affirm that the policy contributes a lot to their stay at university. However, it also reveals some situations that should be re-evaluated and improved.
\end{abstract}

Keywords: Student Assistance; Public Educational Policy; UFRPE.

\title{
Resumén:
}

Esta investigación presenta como elemento principal la relación entre la enseñanza superior y las políticas públicas educativas de asistencia estudiantil, en el intento de una aproximación entre lo que se discute sobre el tema en la literatura especializada, y lo que ocurre efectivamente en una realidad empírica, en el ámbito de una institución de enseñanza superior. La investigación tuvo como principal objetivo analizar la política de asistencia estudiantil de la Universidad Federal Rural de Pernambuco (UFRPE), a partir de la percepción de los estudiantes beneficiados. La importancia de esta investigación está en la posibilidad de discutir la contribución de la asistencia estudiantil comprendiéndola como parte de la política educativa. En cuanto a la metodología, la investigación presentó enfoques cualitativo y cuantitativo, siguiendo etapas complementarias que pretendían contribuir en la recolección, análisis e interpretación de los datos. Para esto, se realizó el levantamiento de datos secundarios sobre las principales temáticas de la investigación, y en el trabajo de campo, se aplicaron cuestionarios con estudiantes beneficiados por la política. Los datos analizados demuestran que la mayoría de los estudiantes evalúa como buena la política de asistencia estudiantil de la UFRPE, así como, afirma que la asistencia estudiantil contribuye mucho a su permanencia en la universidad. Sin embargo, también revela algunas situaciones que necesitan ser reevaluadas y mejoradas.

Palabras clave: Asistencia Estudiantil; Política Pública Educativa; UFRPE.

\section{Introdução}

A educação superior tem como função essencial a formação de sujeitos autônomos, assim como, a construção de conhecimentos integrados à formação crítica e reflexiva. Além de constituir-se como um fator fundamental para o desenvolvimento econômico, social e político do país (DIAS SOBRINHO, 2005).

Nessa perspectiva, a Lei $\mathrm{n}^{-0}$ 13.005/2014 (BRASIL, 2014), que trata sobre o Plano Nacional de Educação (PNE), traz como objetivos nas metas 12, 13 e 14, o aumento do número de matrículas, a elevação da qualidade da educação superior, a ampliação da titulação do corpo docente e o aumento do número de mestres e doutores na população brasileira. Essas metas visam expandir o acesso ao ensino superior, aumentar os anos de estudo da população e estimular a produção de conhecimento.

Com a crescente demanda evidenciada nos últimos anos, o acesso ao nível superior de ensino foi sendo estimulado via distintas estratégias, tais como, ampliação e diversificação de vagas ofertadas, esforços para garantir a permanência dos estudantes e investimentos na qualidade do ensino. Mesmo com tais estratégias, na opinião de Mota 
(2008), a ampliação do acesso ao ensino superior, público ou privado, só adquire sentido quando vislumbrada como um conjunto de projetos que articulam educação básica, pósgraduação, ampliação de acesso e permanência, reestruturação acadêmica, recuperação orçamentária, avaliação e regulação. Dessa forma, com o considerável aumento nas vagas das universidades públicas e no acesso ao ensino superior por parte da população historicamente excluída de toda uma dinâmica educacional, surge o reconhecimento de que tão somente o ingresso na universidade pública não é capaz de garantir a permanência dos estudantes menos favorecidos nas instituições de ensino superior (IES) do país (SGUISSARDI, 2000).

Dessa forma, reconhece-se a necessidade de criar condições para a permanência desses estudantes na universidade, que possam refletir, também, na qualidade do ensino superior. Para Zago (2006), essas condições podem ser criadas através da democratização da educação, o que requer políticas públicas educacionais que possibilitem a expansão e o acesso ao ensino superior. Ao mesmo tempo, essa autora enfatiza que sem a criação de políticas que sejam voltadas para a garantia de permanência dos estudantes nas universidades, torna-se difícil a expansão do ensino superior de qualidade. Nessa mesma linha de pensamento, Carvalho (2006) situa que os dados sobre o perfil dos estudantes no ensino superior indicam que a democratização do ensino é bastante contraditória no Brasil, diante da desigualdade de renda entre as famílias e a reduzida parcela do ensino gratuito e de qualidade.

Como consequência da expansão do acesso e na tentativa de reduzir a desigualdade presente nas IES públicas, foi instituído o Programa Nacional de Assistência Estudantil (Pnaes), pela Portaria Normativa do Ministério da Educação (MEC) n³9/2007, e regulamentado pelo Decreto $\mathrm{n}^{\circ} 7.234 / 2010$. Esse programa estabelece as diretrizes para as ações de assistência estudantil direcionadas aos alunos em vulnerabilidade socioeconômica. E constitui-se como o principal instrumento regulador da assistência estudantil no país. Muitas universidades brasileiras têm buscado implementar o Pnaes, que vem se caracterizando como um mecanismo que visa garantir condições justas de permanência ao estudante no ensino superior. É o caso da UFRPE, onde foi realizada esta pesquisa.

A UFRPE criou por meio da Resolução nº 185/2006 do Conselho Universitário, a Pró-Reitoria de Gestão Estudantil (Progest). Após alteração através de proposta no ano de 2016, pela Resolução nº80/2016, o órgão passou a se chamar Pró-Reitoria de Gestão 
Estudantil e Inclusão (Progesti). A Progesti atende os estudantes em situação de vulnerabilidade socioeconômica no campus Sede, situado no bairro de Dois Irmãos em Recife e possui a seguinte missão:

Incentivar, apoiar, orientar e acompanhar, de forma articulada com as demais pró-reitorias, departamentos acadêmicos, departamentos administrativos e órgãos suplementares, o estudante, em suas múltiplas demandas, no decorrer de sua trajetória estudantil, através de ações afirmativas de permanência nas áreas social, técnico-científica, cultural, política e esportiva (PROGESTI, 2016).

Assim, o presente artigo apresenta uma pesquisa que teve por objetivo analisar a política de assistência estudantil da UFRPE Sede (Campus Dois Irmãos) a partir da percepção dos estudantes beneficiados. Os objetivos específicos foram: caracterizar a política de assistência estudantil da UFRPE Sede (Campus Dois Irmãos) e os estudantes que a acessam; avaliar como as ações de assistência estudantil da UFRPE Sede (Campus Dois Irmãos) têm influenciado na permanência dos estudantes na universidade, no atendimento de suas necessidades acadêmicas e como isso vem se caracterizando. Portanto, este estudo torna-se relevante pela possibilidade de contribuir para a reflexão das políticas públicas educacionais de educação superior no Brasil.

\section{Assistência Estudantil no Brasil e na UFRPE}

A assistência estudantil caracteriza-se como uma política regulamentada recentemente, porém, já era contemplada em algumas instituições superiores brasileiras, desde o nascimento das universidades no Brasil através de ações restritas e com recursos escassos (FONAPRACE, 2001). Entende-se a concepção de assistência estudantil como

Um conjunto de princípios e diretrizes que norteiam a implantação de ações para garantir o acesso, a permanência e a conclusão de cursos de graduação dos estudantes das IFES, na perspectiva da inclusão social, formação ampliada, produção do conhecimento, melhoria dp desempenho acadêmico e da qualidade de vida (FONAPRACE, 2012).

O ensino superior público vem atendendo a uma parcela significativa da população em situação de vulnerabilidade socioeconômica com dificuldades de se manter na universidade. Dessa forma, percebeu-se a necessidade de elaboração de programas de apoio ao estudante e após essas constatações, criou-se um Plano Nacional de Assistência Estudantil pelo Fórum Nacional de Pró-Reitores de Assuntos Comunitários e Estudantis (Fonaprace), com diretrizes norteadoras e alocação de recursos para a assistência estudantil nas Ifes. O MEC, através da Portaria Normativa no 39, de 12 de dezembro de 
2007, instituiu o Plano Nacional de Assistência Estudantil. Baseado neste Plano, foi elaborado o Programa Nacional de Assistência Estudantil - Pnaes, o qual é regulamentado pelo Decreto no 7.234/2010 da Presidência da República. O Pnaes tem como objetivos conforme o Art.2ํ do decreto no 7.234, de 19 de julho de 2010 (BRASIL, 2010):

I - democratizar as condições de permanência dos jovens na educação superior pública federal; II - minimizar os efeitos das desigualdades sociais e regionais na permanência e conclusão da educação superior; III - reduzir as taxas de retenção e evasão; e IV - contribuir para a promoção da inclusão social pela educação (BRASIL, 2010).

O Pnaes tem como intuito oferecer subsídios para que aqueles alunos com baixa renda consigam manter-se nos seus cursos de graduação. Tal medida visa diminuir a desigualdade social e possibilitar a democratização do acesso e da permanência dos estudantes no ensino superior federal. Segundo o Programa, isso será feito por meio de auxílio à moradia estudantil, alimentação, transporte, assistência à saúde, inclusão digital e atividades de cultura, esportes, creche e apoio pedagógico. Nesse sentido, pode-se afirmar que

A promulgação do Programa Nacional de Assistência Estudantil (PNAES) em 12 de dezembro de 2007, representa um marco histórico e de importância fundamental para a questão da assistência estudantil. Essa conquista foi fruto de esforços coletivos de dirigentes, docentes e discentes e representou a consolidação de uma luta histórica em torno da garantia da assistência estudantil enquanto um direito social voltado para a igualdade de oportunidades aos estudantes do ensino superior público (VASCONCELOS, 2009, p. 608).

A Progest, órgão executivo da administração geral, foi criada em 2006 através da Resolução ${ }^{\circ} 185 / 2006$ do Conselho Universitário (CONSU). Em julho de 2016, o artigo $2^{\circ}$ dessa resolução, foi modificado pela Resolução n080/2016 que alterou o nome da PróReitoria de Gestão Estudantil para Pró-Reitoria de Gestão Estudantil e Inclusão (Progesti), com o objetivo de ressaltar a promoção da inclusão dos estudantes em vulnerabilidade socioeconômica da UFRPE.

A Progesti especifica como missão no seu artigo $1^{\circ}$ da resolução $n^{\circ} 237 / 2012$ :

incentivar, apoiar, orientar e acompanhar, de forma articulada com as demais Pró-Reitorias, Departamentos Acadêmicos, Departamentos Administrativos e Órgãos Suplementares, o estudante, em suas múltiplas demandas, no decorrer de sua trajetória Estudantil, sobretudo aqueles de vulnerabilidade sócio econômica, através de ações afirmativas de permanência nas áreas social, técnico-científica, cultural, política e esportiva (UFRPE, 2012). 
No âmbito da política de assistência estudantil da UFRPE, são desenvolvidos programas e ações com o objetivo de ampliar o acesso e permanência no ensino superior através do atendimento aos estudantes em situação de vulnerabilidade socioeconômica. São oferecidos programas nas modalidades de apoio ao discente, apoio à gestante, apoio ao ingressante, residência, promoção de esportes e incentivo à cultura. Os estudantes beneficiados pela assistência estudantil devem atender aos critérios estabelecidos pelo Pnaes, e estar regularmente matriculados no semestre vigente em curso de graduação, concluir o curso dentro do prazo estabelecido pelas normas da UFRPE, estar em situação de vulnerabilidade socioeconômica, que significa possuir renda familiar de até um salário mínimo e meio; além de atender às exigências específicas de cada programa. A seleção desses estudantes é realizada por assistentes sociais que desenvolvem a análise socioeconômica por meio da comprovação da documentação e entrevista social levando em consideração fatores como: renda familiar bruta mensal, número de pessoas do grupo familiar, despesas com moradia e transporte, doenças do grupo familiar, bens patrimoniais do grupo familiar, além de outras condições observadas em conformidade com a política de Assistência Social. De acordo com Back (2017, p. 79), “a situação de vulnerabilidade socioeconômica não se reduz à renda, mas a um conjunto de situações que se expressa pela ausência de direitos, falta de oportunidades, acesso às políticas sociais e outros fatores".

Além desses programas, são desenvolvidas ações como: De volta ao lar; Hospeda Rural; Restaurante Universitário; Apoio à participação em eventos científicos e/ou acadêmicos, Acessibilidade, Programa Bolsa Permanência (PBP) do MEC e os Acompanhamentos pedagógico, psicológico e social dos estudantes.

\section{Metodologia}

Do ponto de vista metodológico, a investigação se baseou no método quanti-quali. A escolha por essa estratégia metodológica deve-se ao fato de que "combinar técnicas de análise quantitativa com técnicas de análise qualitativa proporciona maior nível de credibilidade e validade aos resultados da pesquisa, evitando-se, assim, o reducionismo por uma só opção de análise" (OLIVEIRA, 2012, p. 39). Além disso, como destaca Creswell (2010), a combinação de dados dos tipos qualitativo e quantitativo, pode ocorrer em distintos estágios de uma pesquisa: na coleta, na análise, na interpretação dos dados, ou nas três fases. 
A pesquisa foi realizada por meio de questionário enviado por e-mail e direcionado aos 364 estudantes que possuíam cadastro com e-mail atualizado no banco de dados da Progesti/UFRPE. 0 questionário foi composto por 24 (vinte e quatro) questões fechadas e 1 (uma) aberta, que possibilitou a compreensão de dados relevantes para esta pesquisa. Obteve-se um total de 82 questionários respondidos. A atividade consistiu em colher informações da população beneficiada, como dados gerais, opiniões ou respostas a perguntas formuladas sobre os indicadores que se pretendeu estudar.

A representação dos dados se deu por meio de gráficos e tabelas. Como consta em Marconi e Lakatos (2010), os gráficos podem ser informativos ou analíticos, objetivam dar ao público ou ao investigador um conhecimento da situação real e atual do problema estudado, como também fornecer elementos de interpretação, cálculos, inferências e previsões.

Através das respostas obtidas no questionário, foram desenvolvidos gráficos e tabelas que apresentam os dados da pesquisa. $\mathrm{Na}$ análise desses dados, pretendeu-se promover uma interação dessas informações na busca de uma melhor compreensão do objeto estudado, tendo como técnica a análise de conteúdo. Como referenda Bardin, a análise de conteúdo configura-se como um:

\begin{abstract}
Conjunto de técnicas de análise das comunicações visando obter, por procedimentos sistemáticos e objetivos de descrição do conteúdo das mensagens, indicadores (quantitativos ou não) que permitem a inferência de conhecimentos relativos às condições de produção/recepção (variáveis inferidas) destas mensagens (BARDIN, 1979, p. 42).
\end{abstract}

A partir da análise dos dados coletados, discutiu-se sobre a avaliação dos estudantes beneficiados em relação aos programas de assistência estudantil da UFRPE.

\title{
Resultados e Discussões
}

Acerca do perfil dos estudantes participantes da pesquisa a partir do questionário, foram levantadas informações relevantes que contribuíram para a análise dos dados. 0 primeiro eixo das questões teve como objetivo caracterizar os estudantes beneficiados identificando o seu perfil.

Dos estudantes beneficiados pela assistência estudantil da UFRPE que responderam ao questionário, 53,66\% é do sexo feminino. Esses dados estão em conformidade com os dados gerais sobre o ensino superior no país, desenvolvidos pelo Instituto Nacional de Estudos e Pesquisas Educacionais Anísio Teixeira (Inep). Segundo o 
Inep (2015), o número de ingressantes mulheres na educação superior no ano de 2015 é de $53,9 \%$.

Nessa perspectiva, Leta (2003) considera que a partir da década de 1980, com a expansão de instituições de ensino superior tanto pública quanto privada, aconteceu o que a autora denominou de evolução do número de mulheres matriculadas no ensino superior. Para esta autora, "é evidente a mudança na universidade brasileira no que diz respeito à frequência de mulheres: diferente de algumas poucas décadas atrás, elas hoje são a maioria em boa parte dos cursos de graduação do país" (LETA, 2003, p. 274).

Os estudantes, em sua maioria, possuem estado civil como solteiro, alcançando o percentual de 81,71\%. Esse alto percentual pode ser justificado pelo número elevado de estudantes com faixa etária entre 18 a 21 anos que soma 46,34\% do total de estudantes da pesquisa. Quando cruzados esses dados, a pesquisa aponta que $41,46 \%$ dos estudantes com 18 a 21 anos são solteiros.

Segundo os dados da pesquisa do ano de 2015, do Instituto Brasileiro de Geografia e Estatística (IBGE), do total de estudantes na faixa entre 18 e 24 anos, parcela de 32,9\% frequentava o Ensino Superior em 2004. Em 2014, dos estudantes dessa mesma faixa etária, 58,5\% estavam na faculdade. É um salto de mais de 30 pontos percentuais que representam um dado significativo e mostra que há uma forte tendência de democratização no acesso ao ensino superior. Em contrapartida, o último Censo da Educação Superior divulgado no segundo semestre de 2017 pelo MEC e Inep, apresenta que houve uma diminuição no crescimento das matrículas no ensino superior se comparada aos últimos anos, porém essa diminuição se deu na rede privada, já na rede pública, percebe-se um aumento nesse número como podemos observar na tabela 1 abaixo.

Tabela 1 - Número total de matrículas no ensino superior no Brasil (2012 a 2016)

\begin{tabular}{llll}
\hline ANO & Pública & Privada & TOTAL \\
\hline 2012 & 1.897 .376 & 5.140 .312 & 7.037 .688 \\
2013 & 1.932 .527 & 5.373 .450 & 7.305 .977 \\
2014 & 1.961 .002 & 5.867 .011 & 7.828 .013 \\
2015 & 1.952 .145 & 6.075 .152 & 8.027 .297 \\
2016 & 1.990 .078 & 6.058 .623 & 8.048 .701 \\
\hline
\end{tabular}

Fonte: Macedo (2017). Elaborada a partir dos dados do MEC/Inep (2017)

Até o ano de 2010, a predominância das matrículas no ensino superior era do setor privado. Entretanto, essa queda do número de matrícula observada em 2016 pode ter sido 
consequência da crise econômica e desemprego gerados no atual contexto socioeconômico e político enfrentado no país, causando impactos nesses resultados.

Em relação aos estudantes atendidos pela assistência estudantil, observa-se que os cursos que apresentaram maior quantidade de estudantes foram: Agronomia, Licenciatura Plena em Ciências Biológicas e Bacharelado em Ciências Biológicas. Os cursos que apresentaram menor quantidade de discentes foram: Bacharelado em Ciências Econômicas e Bacharelado em Sistemas de Informação. Quanto à escolha do curso superior, Nogueira (2007) esclarece que as pesquisas sobre o assunto vêm apontando que a distribuição dos indivíduos nos cursos superiores está estatisticamente ligada às suas características sociais, perfil acadêmico, etnia, sexo e idade. E também que, existe um processo de auto seleção complexo na escolha do curso superior.

No que diz respeito à forma de ingresso, 91,46\% dos estudantes pesquisados ingressou na universidade pelo Exame Nacional do Ensino Médio (ENEM). Atualmente, o ENEM é a principal forma de ingresso no ensino superior, principalmente a partir de 2009, quando o MEC criou o Sisu oferecendo a possibilidade dos estudantes fazerem suas opções de inscrições de acordo com as vagas ofertadas nas universidades participantes desse sistema. Quanto ao tipo de escola que o estudante realizou o ensino médio, verificou-se que $85,37 \%$ cursou o ensino médio em escola pública.

Quanto à cor e raça, 40,24\% dos estudantes declaram-se pardos, 30,49\% pretos, 24,39\% brancos, 2,4\% amarelos, 1,2\% indígenas e 1,2\% nenhuma das respostas. Quanto a essa questão, dados do relatório "Desigualdades de Cor/Raça e Sexo entre pessoas que frequentam e titulados na pós-graduação brasileira: 2000 e 2010" desenvolvidos pela Fundação Carlos Chagas (FCC), apontam que a diminuição dos que se autodeclararam brancos na população geral entre os censos de 2000 e 2010 é compensada pela ampliação dos que se declararam pretos e pardos. De acordo com a Síntese dos Indicadores Sociais realizada pelo IBGE em 2004, 16,7\% dos estudantes pretos ou pardos tinham acesso ao ensino superior, enquanto que os estudantes brancos eram 47,2\%. Já em 2014, os alunos pretos ou pardos eram 45,5\%, e os brancos eram 71,4\%. Apesar da grande diferença percentual, nota-se que o aumento da população negra na universidade foi mais significativo nesse período. Um dos fatores que pode explicar esse aumento, se deve à adoção de políticas de ação afirmativa nos últimos anos objetivando a diminuição da desigualdade social entre brancos, negros e indígenas. Quanto a essa questão, a Andifes está iniciando em 2018, a quinta edição da Pesquisa do Perfil Socioeconômico dos 
Estudantes das Universidades Federais. Como discutido anteriormente na seção destinada à política pública de assistência estudantil, esses estudos vêm apresentando uma significativa mudança no perfil dos estudantes de graduação das universidades públicas no Brasil, principalmente, a partir da adoção do ENEM como forma de acesso e da implementação da Lei de Cotas. Os dados têm revelado que negros e pardos juntos correspondem a 47,5\% do total de estudantes das instituições brasileiras de ensino superior público, e que dois terços desses estudantes são oriundos de famílias com renda mensal de até um salário mínimo e meio (ANDIFES, 2018).

A maioria dos estudantes pesquisados, 29, 27\% possuem 4 moradores em casa, 24,39\% tem 3 pessoas, 19,51\% tem 2 pessoas, 13,41\% tem 5 pessoas, 8,54\% tem 6 pessoas, 2,4\% tem 1 pessoa, 1,2\% tem 8 pessoas e 1,2\% tem 9 pessoas. Já quanto à renda mensal da família, 60,98\% tem renda mensal de até 1 salário mínimo, estando abaixo do limite estipulado pelo PNAES que é de um salário mínimo e meio. Seguido de 32,93\% com renda de 2 salários mínimos, 3,7\% tem 3 salários e 2,4\% tem 4 salários mínimos. Segundo o Departamento Intersindical de Estatística e Estudos Socioeconômicos (DIEESE) o salário mínimo necessário para atender às necessidades de uma família com moradia, alimentação, educação, saúde, lazer, vestuário, higiene, transporte e previdência social, como prevê a Constituição Federal de 1988, sendo essa família composta por dois adultos e duas crianças, deveria ser, no mês de abril de 2017, de R\$3.899,66, valor 4,07 vezes maior do que o salário em vigor de $\mathrm{R} \$ 937,00$ para dar conta das necessidades básicas de uma família (DIEESE, 2017). No gráfico 1 abaixo, é possível verificar a relação entre raça e renda nos resultados da pesquisa realizada na assistência estudantil da UFRPE. 
Gráfico 1 - Relação entre raça e renda dos estudantes da assistência estudantil da UFRPE

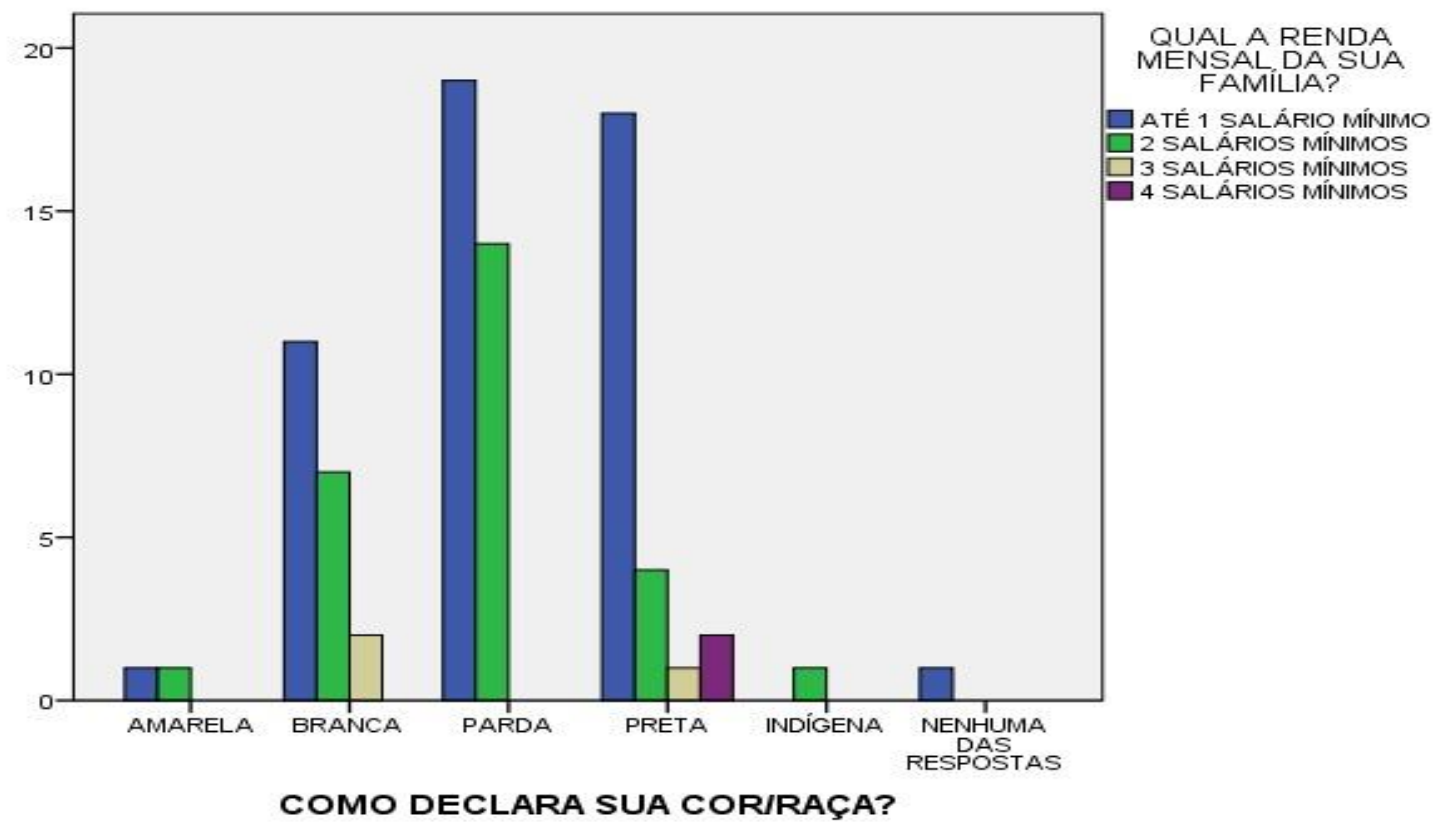

Fonte: Macedo (2017).

De acordo com o cruzamento das informações expostas no gráfico 1 acima, é possível perceber que negros e pardos com renda familiar de até um salário mínimo, aparecem em maior quantidade nos resultados da pesquisa. De acordo com Gentili (2009), "um pouco mais de 200 milhões de latino-americanos são pobres e indigentes e, entre os pobres e indigentes, os que sofrem essa condição de forma mais intensa são os negros e indígenas" (GENTILI, 2009, p. 1066). Dessa forma, é possível perceber que a maioria dos pesquisados vive com uma renda muito abaixo do salário necessário para o atendimento das suas necessidades básicas, inclusive, abaixo também do critério de renda estipulado pelo PNAES. Portanto, é um cenário que repercute no contexto educacional, pois "toda situação de pobreza estrutural ou de intensificação desta, inevitavelmente, exercerá impacto sobre o sistema escolar, questionando, interferindo e fragilizando as condições para o exercício do direito à educação" (GENTILI, 2009, p. 1065).

Quanto aos programas, a maioria dos estudantes 54,9\%, são beneficiados pelo programa de Apoio ao Discente (modalidade transporte). Seguidos de 26,8\% do programa de Apoio ao Discente (modalidade apoio acadêmico) e 18,3\% do programa de Residência Universitária. 0 programa de Apoio à Gestante não obteve representatividade nesta pesquisa. Justifica-se a maior quantidade de estudantes no programa de Apoio ao 
Discente (modalidade transporte), devido à sua elevada oferta de vagas e menor valor do auxílio em comparação aos outros programas.

Quanto ao tempo que faz parte dos programas da assistência estudantil, a maioria dos pesquisados com 36,6\% está no programa entre 7 a 12 meses, seguido de $22 \%$ que faz parte entre 13 a 18 meses. Somando os percentuais acima dos 13 meses, percebe-se que 57,3\% a maioria dos estudantes pesquisados, está na assistência estudantil há pelo menos mais de um ano. Portanto, são pessoas que tem uma vivência razoável dentro da política estudada como mostra a tabela 2 abaixo.

Tabela 2 - Tempo no programa de assistência estudantil da UFRPE

\begin{tabular}{lc}
\hline Tempo que faz parte do programa & $\mathbf{\%}$ \\
\hline Até 6 meses & 6,1 \\
7 a 12 meses & 36,6 \\
13 a 18 meses & 22,0 \\
19 a 24 meses & 11,0 \\
25 a 30 meses & 7,3 \\
31 a 36 meses & 8,5 \\
Mais que 37 meses & 8,5 \\
Total & 100,0 \\
\hline
\end{tabular}

Fonte: Macedo (2017).

Com relação ao segundo eixo das questões, seu objetivo consistiu em analisar a avaliação dos estudantes beneficiados sobre a política de assistência estudantil e sua influência na permanência desse estudante na universidade, assim como, o atendimento das suas necessidades acadêmicas. No que diz respeito à contribuição da assistência estudantil para a permanência do estudante na universidade, $84,1 \%$ dos pesquisados afirmaram que a assistência estudantil da UFRPE contribui muito para a sua permanência na universidade. Esse dado revela a importância da política para a permanência da maioria dos estudantes com baixa renda.

Quanto à avaliação da Política de Assistência Estudantil da UFRPE pelos estudantes pesquisados, a maioria $47,6 \%$ respondeu que considera a política boa, seguido de $28 \%$ muito boa e 20,7\% aceitável. Esse resultado evidencia que a grande maioria avalia positivamente a política.

Quando perguntado sobre como concluiria o curso caso perdesse o benefício da assistência estudantil, 48,8\% dos pesquisados responderam que desistiriam do curso, seguido de $41,5 \%$ que buscariam outra fonte de renda e $24,4 \%$ que buscariam ajuda da 
família. Esse dado revela que o benefício é determinante para a permanência desses estudantes, e também, corrobora a questão referente à contribuição para a permanência, revelando a importância da política para a permanência do aluno na universidade e conclusão do curso.

A questão relativa à prioridade no uso da bolsa/auxílio revela que a maioria $89,9 \%$ utiliza o benefício com transporte, seguido de 67,1\% com alimentação, 56,1\% com despesas de formação universitária, 36,6\% com higiene pessoal e 28,8\% com ajuda familiar. Esses dados mostram que alguns estudantes utilizam o benefício para suprir outras necessidades, revelando além das dificuldades enfrentadas no cotidiano acadêmico, dificuldades vivenciadas no cotidiano familiar. Pode-se dizer que a realidade social experimentada pelos estudantes da UFRPE é resultado do contexto socioeconômico e político apresentado atualmente pelos trabalhadores no Brasil, e que exige para seu enfrentamento, um investimento em políticas de trabalho e renda. Pode-se observar na tabela 3 abaixo as prioridades dos beneficiados no uso do valor da bolsa/auxílio, levando em consideração que essa questão é estimulada e de múltiplas respostas gerando percentuais que podem ultrapassar os $100 \%$.

Tabela 3 - Prioridade no uso do valor da bolsa/auxílio

\begin{tabular}{lc}
\hline Qual (is) a(s) sua (s) prioridade(s) no uso do valor da bolsa/auxílio & $\mathbf{\%}$ \\
que você recebe? & \\
\hline Alimentação & 67,1 \\
Moradia & 9,8 \\
Transporte & 89,9 \\
Higiene pessoal & 36,6 \\
Ajuda familiar & 28,8 \\
Gastos relacionados à formação universitária & 56,1 \\
Saúde & 1,2 \\
\hline
\end{tabular}
Fonte: Macedo (2017).

Quando questionado se possuía outra fonte de renda, 61\% afirmou não ter outra fonte de renda, seguido de 18,3\% com estágio remunerado e 11\% com ajuda da família. Portanto, a maioria dos estudantes pesquisados possui apenas o benefício da assistência estudantil para continuar e concluir os estudos na universidade.

Na questão que pergunta se o benefício é suficiente para suprir as necessidades acadêmicas dos estudantes, 43,9\% respondeu às vezes, seguido de 32,9\% que respondeu nunca e $23,2 \%$ que respondeu geralmente. É possível observar que a política contribui 
para a permanência e conclusão dos estudos na universidade, mas possui fragilidades, visto que se apresenta como insuficiente no que diz respeito ao valor dos benefícios. $\mathrm{Na}$ tabela 4 abaixo, pode-se observar a evolução do reajuste dos benefícios da assistência estudantil da UFRPE.

Tabela 4 - Reajuste dos benefícios da assistência estudantil da UFRPE no período de 2012 a 2016

\begin{tabular}{lccccc}
\multicolumn{1}{c}{ BOLSAS/AUXÍLIOS } & \multicolumn{5}{c}{ PERÍODO/VALORES (R\$) } \\
& $\mathbf{2 0 1 2}$ & $\mathbf{2 0 1 3}$ & $\mathbf{2 0 1 4}$ & $\mathbf{2 0 1 5}$ & $\mathbf{2 0 1 6}$ \\
\hline Apoio acadêmico & 290,00 & 290,00 & 320,00 & 320,00 & 345,00 \\
Bolsa de Informática & 290,00 & 290,00 & 320,00 & 320,00 & -- \\
Bolsa Coral & 290,00 & 290,00 & 320,00 & 320,00 & 345,00 \\
Auxílio Alimentação & 85,00 & 85,00 & 105,00 & 105,00 & 120,00 \\
Auxílio Creche & -- & -- & -- & 320,00 & 345,00 \\
Auxílio Creche 50\% & -- & -- & -- & 160,00 & 172,50 \\
Auxílio Transporte & 60,00 & 60,00 & 75,00 & 75,00 & 90,00 \\
Auxílio Manutenção & 345,00 & 345,00 & 380,00 & 380,00 & 410,00 \\
Auxílio Moradia & 280,00 & 280,00 & 310,00 & 310,00 & 335,00 \\
\hline Fonte: Relatório de Gestão da Progesti 2016. & & & & &
\end{tabular}

Fonte: Relatório de Gestão da Progesti 2016.

Diante da tabela acima, pode-se verificar que no período compreendido entre 2012 a 2013, não houve aumento nos benefícios. Em 2014, houve um aumento entre 15 reais a 35 reais. E em 2016, constata-se um aumento entre 15 reais a 30 reais. Considera-se irrelevante o aumento do valor benefício diante das necessidades dos estudantes. É importante destacar que a bolsa de informática era uma ação que tinha como público estudantes selecionados por professores para exercer contrapartida nos laboratórios de informática da universidade e existiu até o ano de 2016. E a bolsa coral era uma ação de cultura destinada aos estudantes com aptidão musical independente do perfil socioeconômico. Tanto a bolsa informática, como a bolsa coral, não previa o critério socioeconômico nas seleções e eram pagas com o recurso Pnaes até o ano de 2016, quando a bolsa informática foi extinta, e a bolsa coral passou a ser concedida através de editais de seleção apresentando o perfil socioeconômico como um dos critérios de seleção.

No que diz respeito às dificuldades na realização dos estudos, 59,8\% responderam que possuem dificuldades que interferem na vida acadêmica. Ao responder sobre essas dificuldades, $42,7 \%$ dos estudantes pesquisados atribuíram como obstáculo a dificuldade financeira, seguido de 25,6\% como dificuldades de aprendizagem, 23,2\% como metodologia do docente e 15,9\% como problema pessoal. Pode-se perceber que a questão financeira perpassa por todas as esferas, e é crucial e determinante para um bom 
desempenho acadêmico. Na tabela 5 abaixo é possível observar os dados referentes às dificuldades na realização dos estudos, levando em consideração que essa questão é estimulada e de múltiplas respostas gerando percentuais que podem ultrapassar os $100 \%$.

Tabela 5 - Dificuldades na realização dos estudos

\begin{tabular}{lc}
\hline Quais as suas dificuldades na realização dos seus estudos & $\%$ \\
\hline Saúde & 2,4 \\
Problemas pessoais & 15,9 \\
Relacionamento social/interpessoal & 6,1 \\
Dificuldades financeiras & 42,7 \\
Trabalho & 6,1 \\
Metodologia docente & 23,2 \\
Dificuldades de aprendizagem & 25,6 \\
Outras & 3,6 \\
\hline Fonte: Macedo (2017) &
\end{tabular}

Quando questionados se a assistência estudantil desenvolve ações que ajudam nas suas dificuldades acadêmicas, $28 \%$ dos pesquisados responderam geralmente, seguido de $24,4 \%$ às vezes, $20,7 \%$ nunca, $15,9 \%$ raramente e $11 \%$ sempre. Considera-se que parte significativa dos entrevistados, entende que a assistência estudantil da UFRPE possui fragilidades no que tange o desenvolvimento de ações que auxiliem os estudantes no seu desenvolvimento acadêmico.

Em relação à questão aberta do questionário, referente às ações desenvolvidas pela assistência estudantil que ajudam nas dificuldades acadêmicas, 25 estudantes responderam à questão. Dentre eles, 9 especificaram o Restaurante Universitário como ação, 8 o auxílio transporte, 7 a bolsa que recebem, 3 o serviço de psicologia, 2 o serviço de pedagogia e 2 o acompanhamento psicossocial. Por meio desses dados, pode-se inferir que a maioria dos estudantes percebe a alimentação, transporte e renda como um apoio para o seu desenvolvimento acadêmico, antes até de ações de apoio acadêmico como o serviço de psicologia e pedagogia.

Na questão que diz respeito à opinião dos estudantes sobre promoção da igualdade social pela assistência estudantil, a maioria com $41,5 \%$ concorda em parte que a assistência estudantil promove a igualdade social, seguido de 39\% que concorda, 7,3\% que discorda em parte dessa promoção, 6,1\% indeciso e sem opinião e 6,1\% que discorda. Através dos resultados, pode-se inferir que a política tem oportunizado a permanência, porém o estudante não tem se sentido inserido de forma integral e igualitária na 
universidade. Portanto, torna-se necessário mais do que democratização, é preciso garantir a esse estudante o direito à igualdade. Para Cury,

A dialética entre o direito à igualdade e o direito à diferença na educação escolar como dever do Estado e direito do cidadão não é uma relação simples. De um lado, é preciso fazer a defesa da igualdade como princípio de cidadania, da modernidade e do republicanismo. A igualdade é o princípio tanto da não-discriminação quanto ela é o foco pelo qual homens lutaram para eliminar os privilégios de sangue, de etnia, de religião ou de crença. Ela ainda é o norte pelo qual as pessoas lutam para ir reduzindo as desigualdades e eliminando as diferenças discriminatórias. Mas isto não é fácil, já que a heterogeneidade é visível, é sensível e imediatamente perceptível, o que não ocorre com a igualdade. Logo, a relação entre a diferença e a heterogeneidade é mais direta e imediata do que a que se estabelece entre a igualdade e a diferença (CURY, 2002, p. 255).

Os dados referentes à questão de igualdade social revelam que a política parece não ter conseguido promover a igualdade social, e sim, vem abrandado as desigualdades sociais. Dentro dessa perspectiva, Gentili (2009) esclarece que:

A inclusão é um processo democrático integral, que envolve a superação efetiva das condições políticas, econômicas, sociais e culturais que historicamente produzem a exclusão. Por esse motivo, indicadores de melhorias nas condições de acesso a um direito, assim como todo avanço na luta contra a alienação, segregação ou negação de oportunidades, embora sempre suponham grandes conquistas populares, podem não ser suficientes para consagrar o fim dos processos de exclusão historicamente produzidos e que condicionam ou negam esse direito. É apressado, portanto, considerar que um direito está consagrado simplesmente pela superação parcial das condições que o negavam no passado. Em outras palavras, a inclusão educacional é um processo que se constrói em oposição às forças e tendências que produziram e historicamente produzem a negação do direito à educação dos mais pobres e excluídos (GENTILI, 2009, p. 1063).

Quanto à política, pode-se concluir que "não consegue romper a estrutura verticalizada e desigual da sociedade. Melhoram as condições de vida de milhares de jovens, e isso é altamente positivo, porém não alteram radicalmente o panorama social polarizado" (DIAS SOBRINHO, 2011, p. 148).

\section{Considerações Finais}

O estudo revelou que a maioria dos estudantes avalia como boa a política de assistência estudantil da UFRPE, assim como, afirma que a assistência estudantil contribui muito para a sua permanência na universidade. Contudo, também revela algumas situações que precisam ser reavaliadas e melhoradas. A renda familiar da maioria dos 
estudantes beneficiários da política está abaixo da estipulada pelo PNAES, o que demonstra que o perfil desses estudantes é de extrema vulnerabilidade socioeconômica, e por isso, justifica-se que a maioria das respostas dos estudantes pesquisados apresente o valor do benefício como insuficiente para as necessidades desses discentes, assim como, aponte dificuldades financeiras como um entrave na realização dos estudos. Portanto, a questão financeira tem perpassado por todas as esferas sendo crucial para o bom desempenho desses estudantes

A política tem se revelado determinante para permanência desses estudantes na universidade, contudo, uma parte significativa dos discentes pesquisados, entende que a assistência estudantil possui fragilidades no que tange o desenvolvimento de ações que os auxiliem no seu desempenho acadêmico. A pesquisa apresenta também, que os estudantes percebem a inclusão social pela assistência estudantil como parcial. Isso evidencia que a política parece ter conseguido abrandar as desigualdades sociais.

Por fim, acredita-se que os resultados deste estudo podem ser utilizados no sentido de aprimorar as ações de assistência estudantil desenvolvidas pela UFRPE e por outras instituições de ensino.

\section{Referências}

ASSOCIAÇÃO NACIONAL DOS DIRIGENTES DE INSTITUIÇÕES FEDERAIS DE ENSINO SUPERIOR. Andifes realiza nova pesquisa sobre o perfil dos estudantes das Universidades Federais. Brasília, DF: Andifes, 2018. Disponível em: $<$ http://www.andifes.org.br/andifes-realiza-nova-pesquisa-sobre-o-perfil-dosestudantes-das-universidades-federais/>. Acesso em: 20 jan. 2018.

BACK, L. B. Política de assistência estudantil: interfaces com o reconhecimento das diferenças e a promoção da equidade. 2017. 145 f. Dissertação (Mestrado em Ciências Humanas) - Universidade Federal da Fronteira do Sul, Rio Grande do Sul.

BARDIN, L. Análise de conteúdo. Lisboa: Ed. 70, 1979.

BRASIL. Decreto no 7234 de 19 de julho de 2010. Dispõe sobre o Programa Nacional de Assistência Estudantil - PNAES. Brasília, 2010.

BRASIL. IBGE. CENSO da Educação Superior 2016: principais resultados. Disponível em: <http://download.inep.gov.br/educacao_superior/censo_superior/documentos/2016/c enso_superior_tabelas.pdf>. Acesso em: 15 dez. 2017.

Síntese de Indicadores Sociais $2015 . \quad$ Disponível em: http://www.ibge.gov.br/home/estatistica/populacao/condicaodevida/indicadoresmini mos/sinteseindicsociais2015/default.shtm. Acesso em: 12 de julho de 2017.

CARVALHO, C. H. A. O PROUNI no governo Lula e o jogo político em torno do acesso ao ensino superior. Educação e Sociedade, Campinas, v. 27, n. 96, p. 979-1000, out. 2006. 
CRESWELL, J. W. Projeto de pesquisa: métodos qualitativo, quantitativo e misto. 3. Ed. Porto Alegre: Artmed, 2010.

CURY, C. R. J. Direito à educação: direito à igualdade, direito à diferença. Cadernos de Pesquisa, São Paulo, n. 116, p. 245-262, jul. 2002. Disponível em: http://www.scielo.br/scielo.php?script=sci_arttext\&pid=S0100-15742002000200010. Acesso em 17 nov. 2017.

DIAS SOBRINHO, J. Dilemas da educação superior no mundo globalizado: sociedade do conhecimento ou economia do conhecimento? São Paulo: Casa do Psicólogo, 2005.

DIEESE. Pesquisa nacional da Cesta Básica de Alimentos: Salário mínimo nominal e necessário. Disponível em: http://www.dieese.org.br/analisecestabasica/salarioMinimo.html. Acesso em: 12 de julho de 2017.

FONAPRACE. Fórum Nacional de Pró-Reitores de Assuntos Comunitários e Estudantis. Jornal do Fórum Nacional de Pró-Reitores de Assuntos Comunitários e Estudantis. Abril de 2001, Ano 3, n. 5.

. Fórum Nacional De Pró-Reitores De Assuntos Comunitários E Estudantis - Revista Comemorativa: 25 anos: histórias, memórias e múltiplos olhares. Minas Gerais: UFU PROEX, 2012.

GENTILI, P. 0 direito à educação e as dinâmicas de exclusão na América Latina. Educação e Sociedade, Campinas, v. 30, n. 109, p. 1059-1079, set/dez 2009.

GOMES, N. L. Diversidade étnico-racial, inclusão e equidade na educação brasileira: desafios, políticas e práticas. Revista Brasileira de Política e Administração da Educação - v.27, n.1, p. 109-121, jan./abr. 2011.

LETA, Jacqueline. As mulheres na ciência brasileira: crescimento, contrastes e um perfil de sucesso. Estud. av. vol.17 no.49 São Paulo Sept./Dec. 2003. Disponível em: http://www.scielo.br/scielo. Acesso em: 20 dez. 2017

MARCONI, M. de A.; LAKATOS, E. M. Fundamentos de metodologia científica. 7. ed. São Paulo: Atlas, 2010.

MOTA, R. PROUNI: Porta aberta para a inclusão social. Revista PROUNI, Ministério da Educação (MEC), ed. 01, p. 6-7, 2008. Disponível em: <http://prouniportal.mec.gov.br/images/pdf/Revista_ProUni/Revista_ProUni.pdf>.

Acesso em: 15 dez. 2017.

NOGUEIRA, C. M. M. 0 processo de escolha do curso superior: análise sociológica de um momento crucial das trajetórias escolares. In: REUNIÃO ANUAL DA ASSOCIAÇÃO NACIONAL DE PÓS-GRADUAÇÃO E PESQUISA EM EDUCAÇÃO, 30., 2007, Caxambu: Anped, 2007. 30 anos de pesquisa e compromisso social.

OLIVEIRA, M. M. de. Como fazer pesquisa qualitativa. 4. ed. Petrópolis, RJ: Vozes, 2012. PROGESTI. Missão da Progesti. Disponível em: <http://www.progesti.ufrpe.br/br/missao>. Acesso em: 10 out. 2015.
Relatório
de
Gestão
2016.
Disponível
em:

http://www.progesti.ufrpe.br/br/node/33. Acesso em: 19 de julho de 2017. 

contribuição.

SILVA JR, J. R.; SGUISSARDI, V. A educação superior privada no Brasil: novos traços de identidade. In: SGUISSARDI, V. (Org.). Educação superior: velhos e novos desafios. São Paulo: Xamã, 2000.

VASCONCELOS, N. B. Programa de Assistência Estudantil: uma análise da evolução da assistência estudantil ao longo da história da educação superior no Brasil. 2009. Disponível em: www.seer.ufu.br/index.php/emrevista/article/download/.../6598. Acesso em: 09 jul. 2015.

ZAG0, N. Do acesso à permanência no ensino superior: percursos de estudantes universitários de camadas populares. Revista Brasileira de Educação, São Paulo, v. 11, n. 32, p. 1-13, maio/ago. 2006. 


\title{
JORNAL DE POLÍTICAS EduCACIONAIS

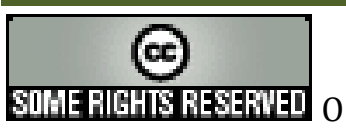

0 Copyright é retido pelo/a autor/a (ou primeiro co-autor) que outorga o direito da primeira publicação ao Jornal de Políticas Educacionais. Mais informação da licença de Creative Commons encontram-se em http://creativecommons.org/licenses/by-nc-nd/2.5. Qualquer outro uso deve ser aprovado em conjunto pelo/s autor/es e pelo periódico.

JoRnAL DE Políticas EdUCACIONAIS é uma publicação do Núcleo de Políticas Educacionais do Setor de Educação da Universidade Federal do Paraná - NuPE/UFPR, em consórcio com a Linha de Pesquisa em Políticas Educacionais do Programa de Pós-Graduação em Educação - PPGE/UFPR, que aceita colaboração, reservando-se o direito de publicar ou não o material espontaneamente enviado à redação. As colaborações devem ser enviadas ao NuPE/UFPR, conforme orientações contidas nas páginas do periódico na internet: http://revistas.ufpr.br/ipe.

\author{
Indexação: \\ BBE - Biblioteca Brasileira de Educação (MEC/INEP) \\ Clase (Base de Datos Bibliográfica de Revistas de Ciencias Sociales y Humanidades) \\ Diadorim - Diretório de Política de Acesso Aberto das Revistas Científicas Brasileiras (IBICT) \\ Google Scholar \\ Index Copernicus \\ Portal de Periódicos (CAPES) \\ SER - Sistema Eletrônico de Revistas da Universidade Federal do Paraná (SER/UFPR) \\ Sumários de Revistas Brasileiras (FUNPEC-RP) \\ DRII - Directory of Research Journals Indexing
}

(Periódico integralmente disponível apenas em via eletrônica)

Jornal de Políticas Educacionais / Núcleo de Políticas Educacionais da Universidade Federal do Paraná -

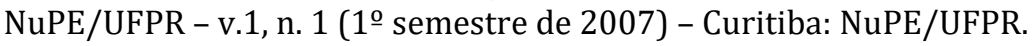

Volume 12, número 10 - Junho de 2018

ISSN 1981-1969

1. Educação - Periódicos. 2. Política Educacional - Periódicos. I. NuPE/UFPR

Comitê Editorial:

Ana Lorena Bruel (UFPR)

Elisângela Scaff (UFPR)

Marcos Alexandre Ferraz (UFPR)

Conselho Editorial:

Andréa Barbosa Gouveia (UFPR), Ângela Hidalgo (UNICENTRO), Ângelo Ricardo de Souza (UFPR), Cesar Gernomino Tello (Universidad Nacional TresFebrero, Argentina),Gladys Beatriz Barreyro (USP), Juca Gil (UFRGS), Jefferson Mainardes (UEPG), João Ferreira de Oliveira (UFG), Luiz Souza Júnior (UFPB), Marcos 

contribuição.

Edgard Bassi (UFSC), Regina Maria Michelotto (UFPR), Robert Verhine (UFBA), Rosana Cruz (UFPI), Rubens Barbosa Camargo (USP), Sebastián Donoso Díaz (Universidad de Talca, Chile), Taís Moura Tavares (UFPR), Theresa Adrião (UNICAMP), Vera Peroni (UFRGS).

\author{
Jornal de Políticas Educacionais \\ Universidade Federal do Paraná \\ Setor de Educação \\ Núcleo de Políticas Educacionais - NuPE/UFPR \\ Rua Gal. Carneiro, 460 - 4ํa andar - Sala 407/C \\ 80.060-150 - Curitiba - PR - Brasil \\ Tel.: 41-3360-5380 \\ jpe@ufpr.br \\ http://revistas.ufpr.br/jpe
}

